Article

\title{
Implementing Defects for Ratiometric Luminescence Thermometry
}

\author{
Joanna Drabik *, Karolina Ledwa $₫$ and Łukasz Marciniak * \\ Institute of Low Temperature and Structure Research, Polish Academy of Sciences, Okólna 2, \\ 50-422 Wroclaw, Poland; k.ledwa@intibs.pl \\ * Correspondence: j.drabik@intibs.pl (J.D.); 1.marciniak@intibs.pl (Ł.M.)
}

Received: 15 June 2020; Accepted: 3 July 2020; Published: 8 July 2020

\begin{abstract}
In luminescence thermometry enabling temperature reading at a distance, an important challenge is to propose new solutions that open measuring and material possibilities. Responding to these needs, in the nanocrystalline phosphors of yttrium oxide $\mathrm{Y}_{2} \mathrm{O}_{3}$ and lutetium oxide $\mathrm{Lu}_{2} \mathrm{O}_{3}$, temperature-dependent emission of trivalent terbium $\mathrm{Tb}^{3+}$ dopant ions was recorded at the excitation wavelength $266 \mathrm{~nm}$. The signal of intensity decreasing with temperature was monitored in the range corresponding to the ${ }^{5} \mathrm{D}_{4} \rightarrow{ }^{7} \mathrm{~F}_{6}$ emission band. On the other hand, defect emission intensity obtained upon $543 \mathrm{~nm}$ excitation increases significantly at elevated temperatures. The opposite thermal monotonicity of these two signals in the same spectral range enabled development of the single band ratiometric luminescent thermometer of as high a relative sensitivity as $4.92 \% /{ }^{\circ} \mathrm{C}$ and $2 \% /{ }^{\circ} \mathrm{C}$ for $\mathrm{Y}_{2} \mathrm{O}_{3}: \mathrm{Tb}^{3+}$ and $\mathrm{Lu}_{2} \mathrm{O}_{3}: \mathrm{Tb}^{3+}$ nanocrystals, respectively. This study presents the first report on luminescent thermometry using defect emission in inorganic phosphors.
\end{abstract}

Keywords: defects; lanthanide oxide; terbium; nanothermometer; luminescent thermometry; phosphor

\section{Introduction}

A whole range of optically active emitters can be successfully used in luminescence thermometry due to the susceptibility of their optical properties to the temperature changes, like: organic dyes, quantum dots (QDs), metal-organic frameworks (MOFs), polymers, nanodiamonds (ND), inorganic nanoparticles doped with lanthanides $\left(\mathrm{Ln}^{3+}\right)$ and transition metal ions (TM) etc. Organic dyes [1-4] usually emit in the visible range upon excitation with ultraviolet light. Their emission is dependent on temperature, because it is affected by the electronic transitions between vibrational states responsible for luminescence. The luminescent properties of QDs, which result from the recombination of the electron-hole pair are strongly dependent both on the host material composition as well as their size [5-7]. In this case, the phonon-related depopulation processes and the energy gap are strongly temperature dependent. Therefore, QDs are often implemented to spectral position- and intensity-based thermometric approaches. However, their use as the source of one of the luminescent signals in more complex ratiometric nanothermometric systems can also be found [8,9]. Luminescent thermometers (LTs) based on MOFs take advantage from the fact that probability of host-to-metal and metal-to-metal energy transfer probabilities are thermally induced, to enable noncontact temperature readout [10-13]. The unlimited number of combinations of various ions and links, enables designing structures with intentional properties. Polymers [14-18], which most often reveal visible luminescence upon UV excitation, are another group of materials useful in LTs. In spite of their relatively low quantum efficiency, they constitute a significant group of nanothermometers due to their good solubility in water and the strong dependence of their luminescence on local environment changes. By combining polymers, for example with organic dyes or QDs, it is possible to obtain very sensitive sensors that use polymer conformational changes. In luminescence thermometry, examples of the use of color 
centers found in diamonds, such as luminescent tin-vacancy [19], have also been noted. Thermally induced shifting of the zero-phonon line as well as a change in the intensity of the emission of these intentionally introduced optically active centers was observed.

Interesting alternatives to already described LTs pose inorganic nanocrystals doped with optically active ions, most often lanthanides [20] or transition metals [21-24]. A number of their advantages, over other groups of material used for LTs, like high chemical and thermal stability and the lack of photobleaching and photoblinking, lead to the great research interest that they have attracted. In this case, the difference in the thermal dependence of particular emission bands enables the implementation of the ratiometric approach. The optimization of the host material composition and the optically active ions enables the alteration of the thermometric properties of this type of luminescent thermometers according to the requirements. Due to the fact that each of those already reported types of LTs possess some drawbacks and there is no universal luminescent temperature sensor, new approaches and new materials that may be implemented to noncontact temperature sensors are still searched for.

In the nanocrystalline lanthanide oxides, broad bands from surface oxygen defects have been noted. They were investigated in e.g., $\mathrm{Y}_{2} \mathrm{O}_{3}$ doped with $\mathrm{Eu}^{3+}[25]$ or $\mathrm{Tb}^{3+}$ [26], in which the defect emission intensity was comparable to that of dopant ions in a certain temperature range. The influence of temperature on the emission of defects has been demonstrated, which led us to the conclusion that such structures could be intentionally used in optical thermometry. Usually, the emission of such structures is quenched with temperature, however, for energy mismatches of excitation radiation, it is possible to note an increase in the intensity of defect emission, which is associated with satellite phonons [25]. In this work, we show for the first time the exploitation of emission of oxygen defects, occurring in rare earth oxides, in excitation-ratiometric approach to luminescence thermometry using $\mathrm{Tb}^{3+}$ ions emission as the luminescent reference. It has been shown that the $\mathrm{Tb}^{3+}$ emission band obtained upon UV excitation decreases at elevated temperatures. On the other hand, the defect emission upon green excitation reveals thermal enhancement. The opposite monotonicity of these two signals integrated in the same spectral range enables the development of single band ratiometric (SBR) luminescent thermometers based on intrinsic defect emission (Figure 1).

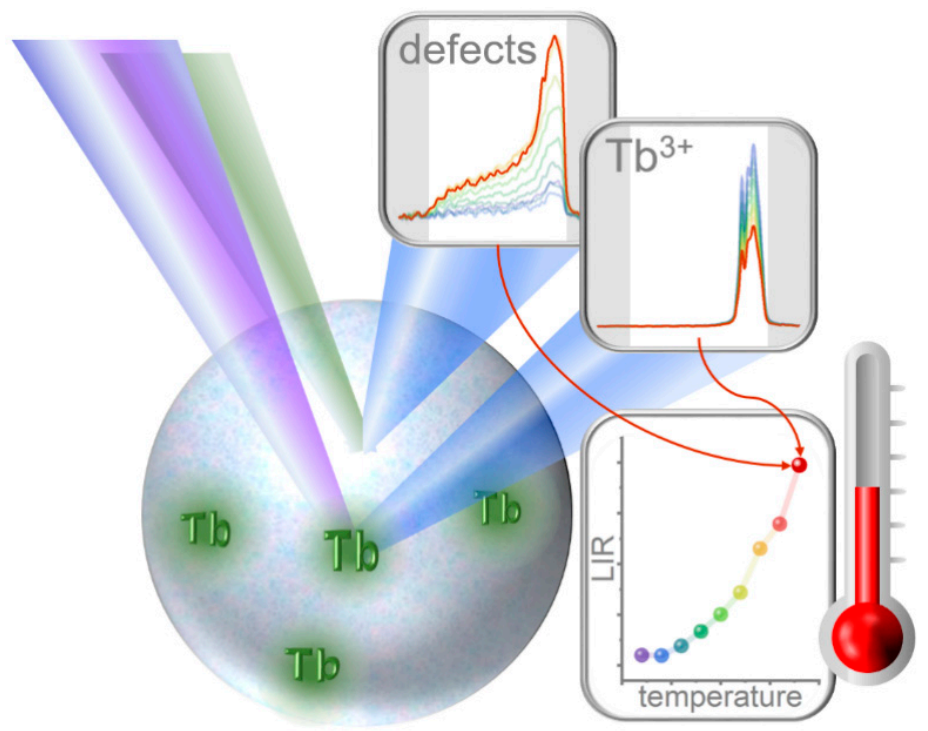

Figure 1. Visualization of the applied measurement scheme: two wavelengths of $266 \mathrm{~nm}$ and $543 \mathrm{~nm}$ exciting $\mathrm{Tb}^{3+}$ ions and luminescent defects, respectively, enabling the local temperature readout on the basis of the luminescence intensity ratio (LIR). 


\section{Materials and Methods}

The nanocrystalline rare earth (RE) oxides phosphors $\left(\mathrm{Y}_{2} \mathrm{O}_{3}\right.$ and $\left.\mathrm{Lu}_{2} \mathrm{O}_{3}\right)$ doped with the trivalent terbium $\mathrm{Tb}^{3+}$ ions $\left(0.05 \%, 0.1 \%, 0.2 \%\right.$ and $0.5 \%$ mole in respect to $\mathrm{Y}^{3+}$ and $\mathrm{Lu}^{3+}$, respectively) were synthesized using the citric acid-assisted method. The following compounds were used as starting materials: yttrium oxide $\left(\mathrm{Y}_{2} \mathrm{O}_{3}\right.$ of $99.999 \%$ purity from Stanford Materials Corporation (SMC, Lake Forest, CA, USA.), lutetium oxide $\left(\mathrm{Lu}_{2} \mathrm{O}_{3}\right.$ of $99.995 \%$ purity from SMC), terbium oxide $\left(\mathrm{Tb}_{4} \mathrm{O}_{7}\right.$ of $99.99 \%$ purity from $\left.\mathrm{SMC}\right)$, nitric acid $\left(\mathrm{HNO}_{3}\right.$ of $65 \%$ purity from Avantor, Gliwice, Slaskie, Poland), and citric acid $\left(\mathrm{C}_{6} \mathrm{H}_{8} \mathrm{O}_{7}\right.$ of $99 \%$ purity from Sigma-Aldrich, Poznan, Wielkopolskie, Poland). The amounts of all the precursors used in the synthesis were stoichiometrically calculated per $0.5 \mathrm{~g}$ of product. The first step was the production of the rare earth nitrates by addition of a significant excess of $\mathrm{HNO}_{3}$ to the water solutions of the oxides. Then, the residual $\mathrm{HNO}_{3}$ was eliminated by a recrystallization process. The citric acid was then added, and the mixture was kept at the heating plate at around $100{ }^{\circ} \mathrm{C}$ in ambient atmosphere for about a day to obtain a resin. The ratio of citric acid moles to metal moles was 1:2. The resultant substance was annealed at $900{ }^{\circ} \mathrm{C}$ for $8 \mathrm{~h}$ in air.

Powder diffraction studies were carried out on a PANalytical X'Pert Pro diffractometer equipped with an Anton Paar TCU $1000 \mathrm{~N}$ temperature control unit using Ni-filtered $\mathrm{Cu} \mathrm{K} \alpha$ radiation $(\mathrm{V}=40 \mathrm{kV}$, $\mathrm{I}=30 \mathrm{~mA}$ ). Rietveld's analysis was performed using the X'Pert HighScore Plus software (version 2.2d (2.2.4), Malvern Panalytical, Malvern, Worecestershire, UK).

Raman spectra were measured on inVia confocal microscope from Renishaw supplied with the Si CCD camera for detection and an $830 \mathrm{~nm}$ excitation line. The spectra were taken at room temperature under $20 \times$ objective. The spatial resolution was lower than $1 \mu \mathrm{m}$.

Transmission electron microscope images were taken using the FEI Tecnai G2 20 X-TWIN microscope supplied with the CCD FEI Eagle 2K camera with a HAADF detector and electron gun with a LaB6 cathode. Moreover, the microscope was supplied with the X-ray microanalyzer EDAX.

The excitation spectra, the photoluminescence decay curves and the quantum yield measurements were measured at room temperature using the FLS980 fluorescence spectrometer from Edinburgh Instruments (version 980, Edinburgh Instruments, Livingston, UK). The measurements were carried out with R928P side window photomultiplier tube from Hamamatsu detector and an integrating sphere for quantum yield measurements. The excitation line was obtained using a $450 \mathrm{~W}$ halogen lamp and the micro-flash lamp.

The temperature-dependent emission spectra were measured using the $266 \mathrm{~nm}$ excitation line from a laser diode or the $543 \mathrm{~nm}$ line from OPOLLETE $355 \mathrm{LD}$ OPO and measured using a Silver-Nova Super Range TEC Spectrometer form Stellarnet (1 nm spectral resolution, Tampa, FL, USA.). The temperature of the sample was controlled using a THMS 600 heating stage from Linkam $\left(0.1{ }^{\circ} \mathrm{C}\right.$ temperature stability and $0.1^{\circ} \mathrm{C}$ set point resolution). Measurements of emission over a wide temperature range with both of the excitation lines were carried out using band pass filters 400-500 $\mathrm{nm}$ from Thorlabs. The temperature was reduced from $200{ }^{\circ} \mathrm{C}$ to $20^{\circ} \mathrm{C}$ with $20^{\circ} \mathrm{C}$ steps, whereas the time needed to stabilize the temperature controller between the double emission measurements was about $2 \mathrm{~min}$.

\section{Results}

The obtained RE oxide nanocrystals underwent structural and morphological characterization. As for the crystal structure, all the studied materials crystallize in the space group I a -3 (206) with a cubic unit cell. Rare earth atoms located inside the ordered volume of nanocrystals are placed in the octahedral sites, having six atoms of oxygen as their nearest neighbors. The X-ray powder diffraction results are shown in Figure 2a. An adequate phase purity was confirmed by the consistency of the received diffractograms with the ICSD pattern data (\#193042, \#428543 for $\mathrm{Y}_{2} \mathrm{O}_{3}$ and $\mathrm{Lu}_{2} \mathrm{O}_{3}$, respectively). No shifts or changes in the relative peak intensities were observed for the increase in the $\mathrm{Tb}^{3+}$ dopant concentration. This is because the $\mathrm{Tb}^{3+}$ ion easily and without a noticeable impact substitutes for $\mathrm{Y}^{3+}$ and $\mathrm{Lu}^{3+}$ ions, due to the fact that those ions have similar ionic radii: $106.3 \mathrm{pm}$, $104.0 \mathrm{pm}$ and $100.1 \mathrm{pm}$, respectively [27]. Based on the Rietveld refinement with respect to the reference 
data, the average sizes of the obtained nanocrystals were estimated (Figure S1). Despite the uncertainty of such analysis associated with the probably significant size distribution, some trend is visible: $\mathrm{Y}_{2} \mathrm{O}_{3}$ nanocrystals are larger than $\mathrm{Lu}_{2} \mathrm{O}_{3}$, which agrees with the values of RE ionic radii. For larger ions, a larger unit cell is obtained (see Figure S2), which can result in such a dependence of crystalline sizes. In fact, a smaller unit cell parameter was determined for $\mathrm{Lu}_{2} \mathrm{O}_{3}$ than for $\mathrm{Y}_{2} \mathrm{O}_{3}$, which were about $1.039 \mathrm{~nm}$ and $1.061 \mathrm{~nm}$, respectively. Only a slight increase in this parameter was recorded in both nanocrystalline matrices when the $\mathrm{Tb}^{3+}$ content was increased. However, due to the chosen synthesis method, the surface of nanocrystals is highly defective. The value of the shortest metal-oxygen distances $(\mathrm{M}-\mathrm{O})$ is also larger in the case of $\mathrm{Y}_{2} \mathrm{O}_{3}(0.2206 \mathrm{~nm})$ with respect to the $\mathrm{Lu}_{2} \mathrm{O}_{3}(0.2189 \mathrm{~nm})$, which indicates that stronger crystal field strength affects the dopant ion in $\mathrm{Lu}_{2} \mathrm{O}_{3}$ (Figure 2b) [28]. Because of slight changes in the electron-phonon coupling, different phonon energies were observed in Raman spectra (Figure 2c). In both RE oxides, the arrangement of the peaks is similar and the appearing modes are marked on the graph (A-singly degenerated, E-doubly degenerated, T-triply degenerated, g-even) [29]. In the case of $\mathrm{Y}_{2} \mathrm{O}_{3}$, the corresponding peaks are shifted towards the lower energies with respect to $\mathrm{Lu}_{2} \mathrm{O}_{3}$, which results from the smaller unit cell of the $\mathrm{Lu}_{2} \mathrm{O}_{3}$ host. The energy of the dominant Raman peak is observed around 378 for $\mathrm{Y}_{2} \mathrm{O}_{3}$ while around $392 \mathrm{~cm}^{-1}$ for $\mathrm{Lu}_{2} \mathrm{O}_{3}$. Moreover, its width increases slightly for $\mathrm{Lu}_{2} \mathrm{O}_{3}$ relative to $\mathrm{Y}_{2} \mathrm{O}_{3}$, which is consistent with the tendency shown by the average size of crystallites (Figure S1), because the smaller the grains, the larger the peak width. The analysis of the TEM images indicates that $\mathrm{Y}_{2} \mathrm{O}_{3}: \mathrm{Tb}^{3+}$ and $\mathrm{Lu}_{2} \mathrm{O}_{3}: \mathrm{Tb}^{3+}$ nanocrystalline powders consist of well crystalized and highly agglomerated particles of the average size of around 56 and $52 \mathrm{~nm}$, respectively (Figure 2d, see also Figure S3). Obtained results are also consistent with average crystallite sizes calculated from XRD data.
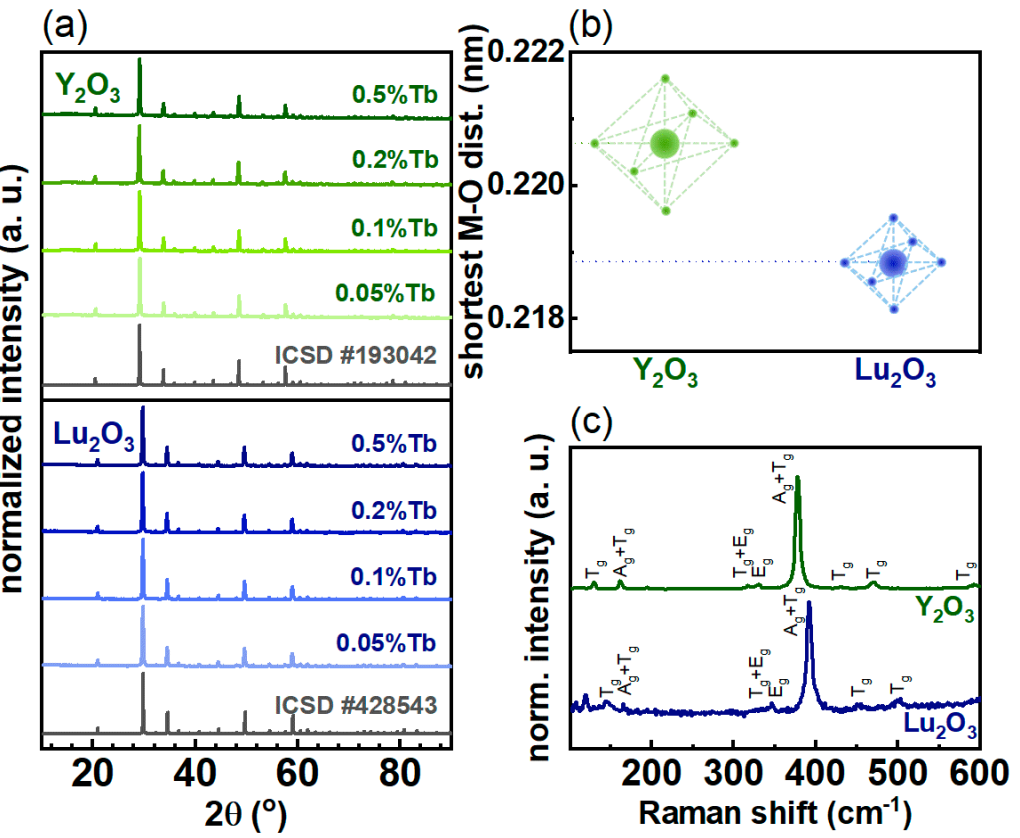

(d)

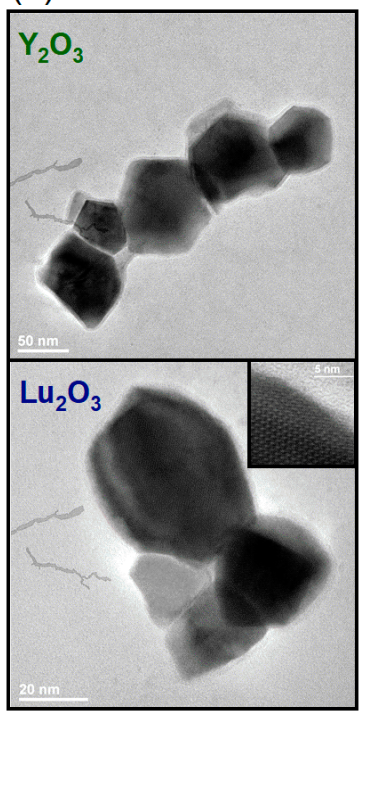

Figure 2. (a) X-ray diffraction patterns of the nanocrystalline rare earth (RE) oxides doped with different concentrations of the $\mathrm{Tb}^{3+}$ ions; (b) Shortest metal-oxygen distances in the given crystals; (c) Raman shift; (d) Transmission Electron Microscopy images of the nanocrystalline RE oxides doped with $0.5 \%$ $\mathrm{Tb}^{3+}$ ions (the appropriate scale bar is presented in each image). 
The optical properties of the studied nanocrystallites were also investigated. The excitation spectra measured at $\lambda_{\mathrm{em}}=540 \mathrm{~nm}$ matching ${ }^{5} \mathrm{D}_{4} \rightarrow{ }^{7} \mathrm{~F}_{5}$ transition is presented in Figure $3 \mathrm{~b}$. In the case of both RE oxides, two broad bands in the ultraviolet range are visible. The first one around $260 \mathrm{~nm}$ corresponds to the spin-allowed $4 f^{8} \rightarrow 4 f^{7} 5 d^{1}$ transition of the $\mathrm{Tb}^{3+}$ ion, while the band around $300 \mathrm{~nm}$ corresponds to the spin-forbidden $4 f \rightarrow 5 d$ transition [30]. Because of the large width of the observed bands, and the fact that the measurements were carried out at room temperature, it is not possible to accurately determine whether the absorption resulting from the presence of defects is visible in the excitation spectrum. For both RE oxides, an increase in the relative intensity of the excitation bands of $\mathrm{Tb}^{3+}$ ions was observed for higher concentrations of $\mathrm{Tb}^{3+}$ ions in the crystalline matrix. This is due to the fact that a larger amount of $\mathrm{Tb}^{3+}$ ions results in the increase of the absorption cross-section, which in turn causes stronger emission. Due to the relatively large energy separation between ${ }^{5} \mathrm{D}_{4}$ and next lower laying energy state $\left({ }^{7} \mathrm{~F}_{0}\right)$ and the distinctive energy level scheme of $\mathrm{Tb}^{3+}$ ions, the ${ }^{5} \mathrm{D}_{4}$ emitting state is barely affected by either multiphonon depopulation or cross relaxation processes. Therefore, an increase of the dopant concentration results in the enhancement of the emission intensity. The representative emission spectra measured at $\lambda_{\text {exc }}=266 \mathrm{~nm}$ for RE oxides with $0.5 \% \mathrm{~Tb}^{3+}$ shown in Figure $3 \mathrm{c}$ consist of a series of bands around 490,544,584, 623, 650, 666 and $685 \mathrm{~nm}$ that correspond to the transitions from the ${ }^{5} \mathrm{D}_{4}$ level to the ${ }^{7} F_{J}$ sublevels $\left(J=6,5,4,3,2,1\right.$ and 0 , respectively). Although the emission spectra of $\mathrm{Tb}^{3+}$ doped RE oxides are very similar qualitatively, there is a large quantitative difference in the absolute brightness of emissions. Upon $266 \mathrm{~nm}$ resonant excitation, stronger emission intensity is observed for $\mathrm{Y}_{2} \mathrm{O}_{3}: \mathrm{Tb}^{3+}$, which is confirmed by quantum yield measurements presented in Figure S4. Moreover, with the increase of $\mathrm{Tb}^{3+}$ ion concentration, the quantum yield increases for each RE oxide. This effect is related to the fact that, in the case of nanocrystals, $\mathrm{Ln}^{3+}$ ions prefer to occupy defective surface positions, which are strongly quenched by the surface-related nonradiative processes [31]. The increase of $\mathrm{Tb}^{3+}$ concentration leads to the higher probability of less surface-affected sites' occupation in the core part of the nanocrystals. Additionally, as was already mentioned, the concentration quenching is not very probable in the case of the ${ }^{5} \mathrm{D}_{4}$ state. Synergy of these two effects causes the enhancement of emission intensity and luminescence quantum yield with enlargement of the $\mathrm{Tb}^{3+}$ amount. It is therefore evidenced that the surface is strongly defected in the case of the investigated nanocrystals. The obtained luminescence decay curves are presented in Figure $3 \mathrm{~d}$ for the representative $0.5 \% \mathrm{of}^{3+}$ concentration. The lifetime elongation of the ${ }^{5} \mathrm{D}_{4}$ energy state of $\mathrm{Tb}^{3+}$ ions in the $\mathrm{Lu}_{2} \mathrm{O}_{3}$, with respect to $\mathrm{Y}_{2} \mathrm{O}_{3}$, is associated with the higher spin-orbital coupling in the case of $\mathrm{Lu}_{2} \mathrm{O}_{3}$ nanocrystals. For the lowest $\mathrm{Tb}^{3+}$ concentration under investigation, the lifetimes of $0.90 \mathrm{~ms}$ and $0.93 \mathrm{~ms}$ were obtained, for $\mathrm{Y}_{2} \mathrm{O}_{3}$ and $\mathrm{Lu}_{2} \mathrm{O}_{3}$, respectively. For a concentration of $0.5 \% \mathrm{~Tb}^{3+}$, for which the luminescence decay curves are presented in Figure 3d, the obtained lifetime values were 0.86 for $\mathrm{Y}_{2} \mathrm{O}_{3}$ and 0.89 for $\mathrm{Lu}_{2} \mathrm{O}_{3}$. Decay times also show a dependence on $\mathrm{Tb}^{3+}$ concentration. The lifetimes determined by single-exponent fit are shown in Figure S5. It was observed that for the tenfold increase in concentration of $\mathrm{Tb}^{3+}$, shortening of average lifetimes reached only $4-7 \%$ of the initial value obtained for the lowest dopant concentration. For $\mathrm{Y}_{2} \mathrm{O}_{3}$, the change from $0.90 \mathrm{~ms}$ to $0.86 \mathrm{~ms}$ was noted for the increase in $\mathrm{Tb}^{3+}$ content in the matrix from $0.05 \%$ to $0.5 \%$, whereas for $\mathrm{Lu}_{2} \mathrm{O}_{3}$ a change from $0.93 \mathrm{~ms}$ to $0.89 \mathrm{~ms}$ was observed. The shortening of lifetimes as the $\mathrm{Tb}^{3+}$ concentration increases results from the fact that the average distance between ions decreases, which in turn opens the paths of energy migration among excited states of $\mathrm{Tb}^{3+}$ ions to the surface quenchers. However, in this case, the shortening of the lifetimes for higher $\mathrm{Tb}^{3+}$ concentrations have no direct effect on the intensity of emissions, because the competitive process associated with the increase in the number of emitters located in the nanocrystal volume is dominant. That is why in the excitation spectrum the intensity of the emission band at $540 \mathrm{~nm}$ increases for higher $\mathrm{Tb}^{3+}$ concentrations (Figure $3 \mathrm{~b}$ ). 

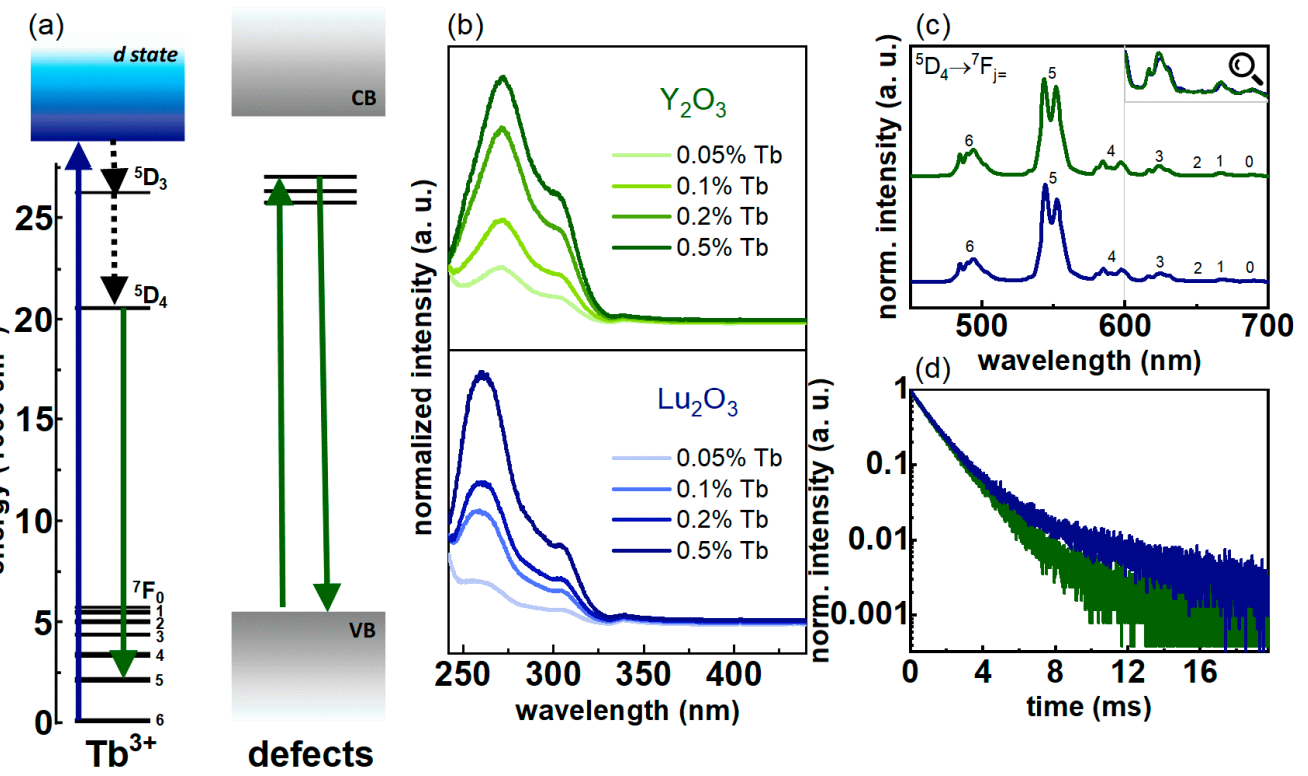

Figure 3. (a) Energy schemes of the luminescent centres present in the investigated RE oxides doped with $\mathrm{Tb}^{3+} ;(\mathbf{b})$ Excitation spectra $\left(\lambda_{\mathrm{em}}=540 \mathrm{~nm}\right)$ of the RE oxides doped with different concentrations of the $\mathrm{Tb}^{3+}$ ions (normalized to the last obtained value); (c) Emission spectra $\left(\lambda_{\text {exc }}=266 \mathrm{~nm}\right.$ ) measured at room temperature for the RE oxides doped with $0.5 \% \mathrm{~Tb}^{3+}$; (d) Luminescence decay curves $\left(\lambda_{\text {exc }}=375 \mathrm{~nm}\right.$, $\left.\lambda_{\mathrm{em}}=540 \mathrm{~nm}\right)$.

The luminescent properties of the obtained RE oxides nanocrystals doped with $\mathrm{Tb}^{3+}$ ions were investigated in a wide temperature range from 20 to $200{ }^{\circ} \mathrm{C}$ upon $\lambda_{\text {exc }}=266 \mathrm{~nm}$ and $\lambda_{\text {exc }}=543 \mathrm{~nm}$ and an appropriate band pass $400-500 \mathrm{~nm}$ filter. It was estimated from the excitation spectra that the $266 \mathrm{~nm}$ excitation line is suitable for the direct resonant excitation of $\mathrm{Tb}^{3+}$ ions. This ultraviolet line causes the $4 f \rightarrow 5 d$ transitions of $\mathrm{Tb}^{3+}$ ions, and then leads to the population of ${ }^{5} \mathrm{D}_{3}$ and ${ }^{5} \mathrm{D}_{4}$ levels from which the emission occurs. However, the emission from the ${ }^{5} \mathrm{D}_{3}$ level is negligible, which may result from the probable $\left\{{ }^{5} \mathrm{D}_{4},{ }^{7} \mathrm{~F}_{6}\right\} \leftrightarrow\left\{{ }^{5} \mathrm{D}_{3},{ }^{7} \mathrm{~F}_{0}\right\}$ cross-relaxation processes. The representative thermal evolution of the $\mathrm{Y}_{2} \mathrm{O}_{3}: 0.5 \% \mathrm{~Tb}^{3+}$ emission spectra in the monitored spectral range is shown in Figure 4a. Only one emission band associated with the ${ }^{5} \mathrm{D}_{4} \rightarrow{ }^{7} \mathrm{~F}_{6}$ transition is observed in this spectral range, the intensity of which decreases with increasing temperature. This effect may be associated with either multiphonon depopulation of the ${ }^{5} \mathrm{D}_{4}$ state, of which probability is dependent on temperature, or with a decrease in the absorption cross-section as the temperature increases resulting from the increase in electron-phonon coupling [32]. However, due to the large energy separation between ${ }^{5} \mathrm{D}_{4}$ and ${ }^{7} \mathrm{~F}_{6}$ states and the required number of phonons to bridge this gap, the thermally-induced enhancement of multiphonon nonradiative processes is not sufficiently efficient to explain the observed thermal dependence. Therefore, as it was proved in the course of our previous studies [32], the temperature-dependent change of the absorption cross section is the dominant process responsible for the lowering of the ${ }^{5} \mathrm{D}_{4} \rightarrow{ }^{7} \mathrm{~F}_{\mathrm{J}}$ emission of $\mathrm{Tb}^{3+}$ ions. On the other hand, when an excitation wavelength was used that was not in resonance with the absorption from the ground state of $\mathrm{Tb}^{3+}$, a peculiar broadband emission was found (Figure $4 \mathrm{~b}$ ). The intensity of this emission band cut-off by the used shortpass optical filter increases at elevated temperatures. To verify the source of this broadband emission, a similar measurement was performed on the $\mathrm{Y}_{2} \mathrm{O}_{3}$ microcrystalline powder. The performed studies indicate that the similar shape of emission bands was noticed in this case, however of significantly lower intensity (Figure S6). This excluded the contribution of $\mathrm{Tb}^{3+}$ ions in the generation of broadband emission. As reported previously, RE oxides exhibit intrinsic luminescent properties associated with optically active defects [25,26]. Huang et al. [33] reported that, in the case of nanocrystalline $\mathrm{Y}_{2} \mathrm{O}_{3}$, the peak observed in the X-ray photoelectron spectroscopy (XPS) corresponding to binding energy of $\mathrm{O} 1 \mathrm{~s}$ was significantly broader with respect to those observed for 
their microcrystalline counterpart. This clearly indicated the presence of different chemical states of $\mathrm{O} 1 \mathrm{~s}$ ions in the $\mathrm{Y}_{2} \mathrm{O}_{3}$ nanocrystals related to the defect states. Broad defect emission was previously reported for other oxides i.e., $\mathrm{ZnO}$, for which a heterogeneously broadened band ranging from 400 to $600 \mathrm{~nm}$ was reported by Karthikeyan et al. [34]. Foch et al. reported that the position of the defects band maximum in $\mathrm{Si}+$ implemented $\mathrm{SiO}_{2}$ can be altered by the preparation condition. The enhancement of the defect emission intensity in the $\mathrm{Y}_{2} \mathrm{O}_{3}$ and $\mathrm{Lu}_{2} \mathrm{O}_{3}$ nanocrystals with respect to the microcrystalline counterpart may suggest that mainly surface defects are involved in this process. Interestingly the emission intensity of defect states increases with temperature. This is probably associated with the fact that excitation wavelength reaches the sideband of the defects absorption band and, at an elevated temperature, the broadening of the absorption band leads to the more efficient pumping of defect emission. Confirmation of this hypothesis is the fact that in the case of the $\mathrm{Y}_{2} \mathrm{O}_{3}$ microcrystals, for which the presence of much narrower absorption band is expected, defect emission can be observed only above $140{ }^{\circ} \mathrm{C}$. The abovementioned emission characteristics for each of the used laser lines were tested for both RE oxide matrices and for different concentrations of $\mathrm{Tb}^{3+}$. $\mathrm{The}^{\mathrm{T} b^{3+}}$ emission intensity obtained upon $\lambda_{\text {exc }}=266 \mathrm{~nm}$ was integrated in the range corresponding to the ${ }^{5} \mathrm{D}_{4} \rightarrow{ }^{7} \mathrm{~F}_{6}$ band and its temperature dependence was depicted in Figure 4c. There is a gradual decrease in the intensity of emission when the temperature increases from 20 to $200{ }^{\circ} \mathrm{C}$ : for $\mathrm{Y}_{2} \mathrm{O}_{3}$, a decrease to about $60 \%$ of the initial value was recorded, while for $\mathrm{Lu}_{2} \mathrm{O}_{3}$, this decrease is greater, to about $40-50 \%$, which is related to the crystal field strength. On the other hand, upon $\lambda_{\text {exc }}=543 \mathrm{~nm}$, significantly, over 5-fold enhancement of defect emission intensity at elevated temperature was observed (Figure 4d), while for the $\mathrm{Y}_{2} \mathrm{O}_{3}: 0.05 \% \mathrm{~Tb}^{3+}$ nanocrystals even 10-fold enhancement of emission intensity was found. The opposite thermal monotonicity of two signals: (1) luminescence of $\mathrm{Tb}^{3+}$ ions and (2) defect emission, which occur in the same spectral range upon different $\lambda_{\text {exc }}$, enables development of the SBR luminescent thermometers based on $\mathrm{Y}_{2} \mathrm{O}_{3}: \mathrm{Tb}^{3+}$ and $\mathrm{Lu}_{2} \mathrm{O}_{3}: \mathrm{Tb}^{3+}$ nanocrystals. In order to verify the performance of nanocrystals under investigation to noncontact temperature sensing, the ratio of integral luminescence intensities (LIR) upon $\lambda_{\mathrm{exc}}=266 \mathrm{~nm}$ and $\lambda_{\mathrm{exc}}=543 \mathrm{~nm}$ calculated in the same spectral range was determined:

$$
L I R=\frac{I\left[T b^{3+}\right]}{I[\text { defects }]}=\frac{\int_{400 n m}^{500 n m} I(T)_{\lambda e x c}=266 n m}{\int_{400 n m}^{500 n m} I(T)_{\lambda e x c}=543 n m} d \lambda
$$

As shown in Figure 4e, a 12-fold enhancement of the LIR for $\mathrm{Y}_{2} \mathrm{O}_{3}: \mathrm{Tb}^{3+}$ nanocrystals can be observed in the $40-200{ }^{\circ} \mathrm{C}$ temperature range. In the case of the $\mathrm{Lu}_{2} \mathrm{O}_{3}: \mathrm{Tb}^{3+}$ nanocrystals observed, LIR's thermal enhancement was only slightly lower due to the fact that although the thermally induced defect emission intensity was significantly lower with respect to the $\mathrm{Y}_{2} \mathrm{O}_{3}: \mathrm{Tb}^{3+}$ counterpart, the $\mathrm{Tb}^{3+}$ emission intensity was quenched faster in this case. The quantitative analysis of the thermally induced LIR's changes is provided by the calculation of the relative sensitivity $\left(S_{r}\right)$ of SBR LT to temperature changes defined as follows:

$$
S_{r}=\frac{1}{L I R} \frac{\Delta L I R}{\Delta T} \cdot 100 \%
$$

where $\Delta L I R$ represents the change of $L I R$ corresponding to $\Delta T$ change of temperature. The maps presenting the thermal dependence of $S_{r}$ for different dopant concentration shown in Figure $4 \mathrm{~g}$ indicate that in the case of $\mathrm{Y}_{2} \mathrm{O}_{3}: \mathrm{Tb}^{3+}$ nanocrystals, there is no correlation between dopant concentration and the $\mathrm{S}_{\mathrm{r}}$. The highest $S_{r}$ values were found in the $60-100{ }^{\circ} \mathrm{C}$ temperature range, for which with the maximum $S_{r}=4.92 \% /{ }^{\circ} \mathrm{C}$ at $40{ }^{\circ} \mathrm{C}$ for $\mathrm{Y}_{2} \mathrm{O}_{3}: 0.05 \% \mathrm{~Tb}^{3+}$. On the other hand, in the case of $\mathrm{Lu}_{2} \mathrm{O}_{3}: \mathrm{Tb}^{3+}$ nanocrystals, the increase of dopant concentration leads to the gradual enhancement of the $S_{r}$ value. This effect may result from the difference in the ionic radii of $\mathrm{Lu}^{3+}$ and $\mathrm{Tb}^{3+}$. The increase of the dopant ion concentration of larger ionic radii with respect to the substituted one results in the generation of 
the larger number of defect states. The analogous difference in the ionic radii in the case of $\mathrm{Y}_{2} \mathrm{O}_{3}: \mathrm{Tb}^{3+}$ nanocrystals is only slight.

(a) Measurement temperature

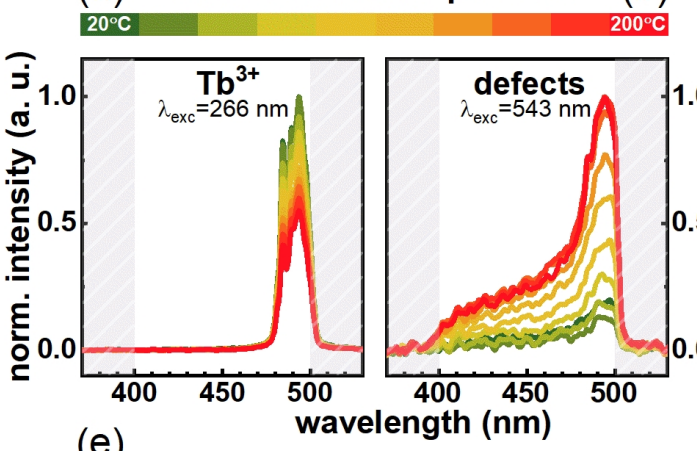

(b)

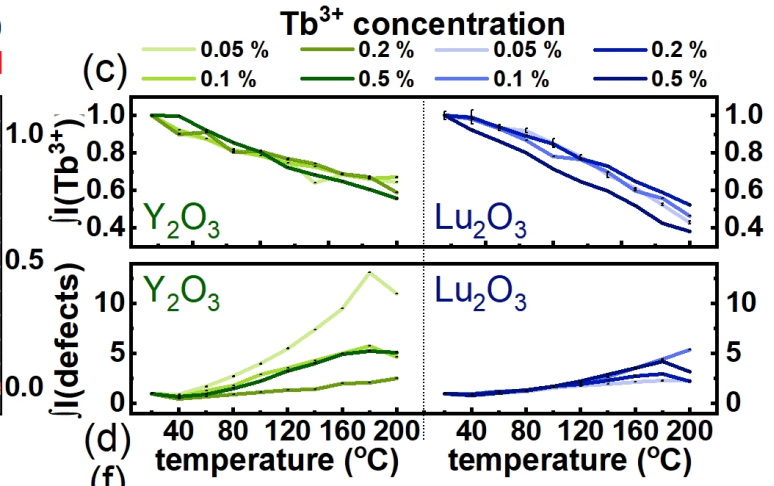

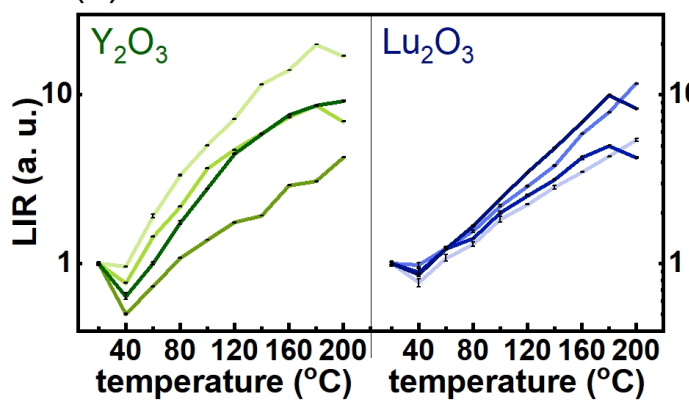

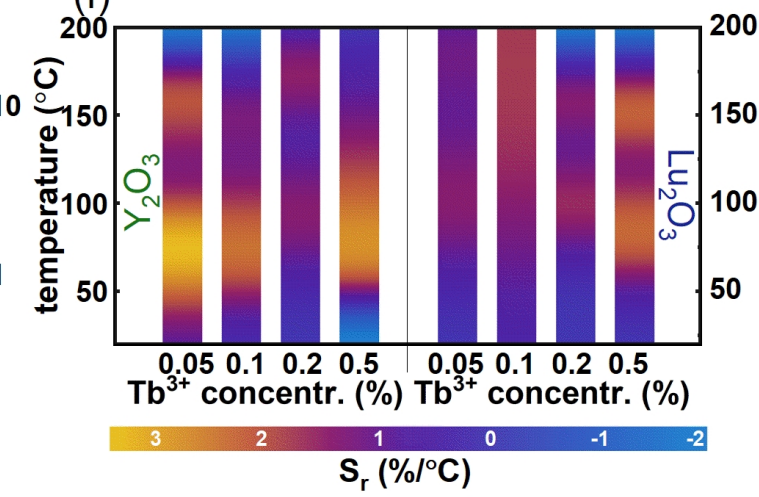

Figure 4. (a). Representative thermal evolution of the emission spectra for $\mathrm{Y} 2 \mathrm{O} 3: 0.5 \% \mathrm{~Tb} 3+$ under $266 \mathrm{~nm}$ and (b) under $543 \mathrm{~nm}$ excitation; (c) Thermal evolution of the integrated RE oxides doped with different $\mathrm{Tb} 3+$ ions emission intensity under $266 \mathrm{~nm}$ and (d) $543 \mathrm{~nm}$ excitation; (e) Luminescent intensity ratio; (f) Relative sensitivity.

\section{Conclusions}

In this work, to the best of our knowledge, for the first-time defect emission of oxide nanoparticles was implemented to noncontact temperature sensing. In order to determine the usefulness for luminescence thermometry, the spectroscopic properties of $\mathrm{Y}_{2} \mathrm{O}_{3}: \mathrm{Tb}^{3+}$ and $\mathrm{Lu}_{2} \mathrm{O}_{3}: \mathrm{Tb}^{3+}$ nanoparticles were examined in a wide temperature range. In was found that the emission intensity of $\mathrm{Tb}^{3+}$ bands associated with the ${ }^{5} \mathrm{D}_{4} \rightarrow{ }^{7} \mathrm{~F}_{\mathrm{J}}$ electronic transition obtained upon $\lambda_{\mathrm{exc}}=266 \mathrm{~nm}$ decreases with temperature. This thermal quenching process was explained in terms of lowered absorption cross section at the excitation wavelength at elevated temperatures. On the other hand, emission intensity of the defect states increases significantly by one order of magnitude in the temperature range under investigation. The comparative studies with the micro sized counterparts reveal the dominant contribution of the surface states in the generation of the emission. The opposite thermal dependence of these two independently excited luminescent signals enabled the development of a single band ratiometric luminescent thermometer. The high thermometric performance of the presented approach was confirmed by the high $\mathrm{S}_{\mathrm{r}}$ values as $4.92 \% /{ }^{\circ} \mathrm{C}$ for $\mathrm{Y}_{2} \mathrm{O}_{3}: 0.05 \% \mathrm{~Tb}^{3+}$ and $2 \% /{ }^{\circ} \mathrm{C}$ for $\mathrm{Lu}_{2} \mathrm{O}_{3}: 0.5 \% \mathrm{~Tb}^{3+}$ nanocrystals. Additionally, it was found that the increase of the $\mathrm{Tb}^{3+}$ concentration in $\mathrm{Lu}_{2} \mathrm{O}_{3}$ nanocrystals enhances the $\mathrm{S}_{\mathrm{r}}$ values that were discussed in terms of higher probability of the defect creation in this host material associated with the difference in the ionic radii between $\mathrm{Lu}^{3+}$ and $\mathrm{Tb}^{3+}$ ions. The use of this new type of optically active center opens up a number of new possibilities and the high relative sensitivities achieved indicate that this achievement should not be overlooked and ought to be further developed. 
Supplementary Materials: The following are available online at http://www.mdpi.com/2079-4991/10/7/1333/s1, Figure S1: Calculated crystalline sizes of the RE oxides doped with different $\mathrm{Tb}^{3+}$ concentrations; Figure S2: Calculated cell parameters for the RE oxides doped with different $\mathrm{Tb}^{3+}$ concentrations; Figure S3. Transmission Electron Microscopy images of the nanocrystalline RE oxides doped with $0.5 \% \mathrm{~Tb}^{3+}$ ions (the appropriate scale bar is presented in each image); Figure S4: Quantum yield $\left(\lambda_{\mathrm{exc}}=266 \mathrm{~nm}\right)$ for the RE oxides doped with different $\mathrm{Tb}^{3+}$ concentrations; Figure S5: Average lifetimes determined from the luminescence decay curves for the RE oxides doped with different $\mathrm{Tb}^{3+}$ concentrations; Figure S6: Comparison of emission spectra $\left(\lambda_{\text {exc }}=543 \mathrm{~nm}\right)$ of microcrystalline precursor $\mathrm{Y}_{2} \mathrm{O}_{3}$ (of $99.999 \%$ purity from Stanford Materials Corporation) with synthesized nanocrystalline $\mathrm{Y}_{2} \mathrm{O}_{3}: 0.5 \% \mathrm{~Tb}^{3+}$ at the same temperature.

Author Contributions: Synthesis, J.D.; methodology, Ł.M., K.L.; investigation and measurements, J.D., K.L.; data analysis, J.D., K.L. and Ł.M.; writing—original draft preparation, J.D.; writing-review and editing, Ł.M.; visualization, J.D. and Ł.M. All authors have read and agreed to the published version of the manuscript.

Funding: This research was funded by National Science Center Poland (NCN) under project No. DEC-2017/27/B/ST5/02557.

Acknowledgments: This work was supported by National Science Center Poland (NCN) under project No. DEC-2017/27/B/ST5/02557.

Conflicts of Interest: The authors declare no conflict of interest. The funders had no role in the design of the study; in the collection, analyses, or interpretation of data; in the writing of the manuscript, or in the decision to publish the results.

\section{References}

1. Xie, T.-R.; Liu, C.-F.; Kang, J.-S. Dye-based mito-thermometry and its application in thermogenesis of brown adipocytes. Biophys. Rep. 2017, 3, 85-91. [CrossRef] [PubMed]

2. Ross, D.; Gaitan, M.; Locascio, L.E. Temperature measurement in microfluidic systems using a temperature-dependent fluorescent dye. Anal. Chem. 2001, 73, 4117-4123. [CrossRef] [PubMed]

3. Itoh, H.; Arai, S.; Sudhaharan, T.; Lee, S.-C.; Chang, Y.-T.; Ishiwata, S.; Suzuki, M.; Lane, E.B. Direct organelle thermometry with fluorescence lifetime imaging microscopy in single myotubes. Chem. Commun. 2016, 52, 4458-4461. [CrossRef]

4. Carlos, L.D.; Palacio, F. Thermometry at the Nanoscale: Techniques and Selected Applications; The Royal Society of Chemistry: Cambridge, UK, 2016. [CrossRef]

5. Maestro, L.M.; Ridruguez, E.M.; Rodriguez, F.S.; Cruz, I.; Juarranz, A.; Naccache, R.; Vetrone, F.; Jaque, D.; Capobianco, J.A.; Sole, J.G. CdSe quantum dots for two-photon fluorescence thermal imaging. Nanoletters 2010, 10, 5109-5115. [CrossRef]

6. Maestro, L.M.; Jacinto, C.; Silva, U.R.; Vetrone, F.; Capobianco, J.A.; Jaque, D.; Sole, J.G. CdTe quantum dots as nanothermometers: Towards highly sensitive thermal imaging. Small 2011, 7, 1774-1778. [CrossRef]

7. Lu, M.; Duan, Y.; Song, Y.; Tan, J.; Zhou, L. Green preparation of versatile nitrogen-doped carbon quantum dots from watermelon juice for cell imaging, detection of $\mathrm{Fe}^{3+}$ ions and cysteine, and optical thermometry. J. Mol. Liq. 2018, 269, 766-774. [CrossRef]

8. Lee, J.; Govorov, A.O.; Kotov, N.A. Nanoparticle assemblies with molecular springs: A nanoscale thermometer. Angew. Chemie. Int. Ed. 2005, 44, 7439-7442. [CrossRef]

9. Kalytchuk, S.; Adam, M.; Tomanec, O.; Zboril, R.; Gaponik, N.; Rogach, A.L. Sodium chloride protected $\mathrm{CdHgTe}$ quantum dot based solid-state near-infrared luminophore for light-emitting devices and luminescence thermometry. ACS Photonics 2017, 4, 1459-1465. [CrossRef]

10. Cui, Y.; Zhu, F.; Chen, B.; Qian, G. Metal-organic frameworks for luminescence thermometry. Chem. Commun. 2015, 51, 7420-7431. [CrossRef]

11. Zhou, Y.; Yan, B.; Lei, F. Postsynthetic lanthanide functionalization of nanosized metal-organic frameworks for highly sensitive ratiometric luminescent thermometry. Chem. Commun. 2014, 50, 15235-15238. [CrossRef] [PubMed]

12. Wang, K.M.; Du, L.; Ma, Y.L.; Zhao, Q.H. Selective sensing of 2,4,6-trinitrophenol and detection of the ultralow temperature based on a dual-functional MOF as a luminescent sensor. Inorg. Chem. Commun. 2016, 68, 45-49. [CrossRef] 
13. Cui, Y.; Song, R.; Yu, J.; Liu, M.; Wang, Z.; Wu, C.; Yang, Y.; Wang, Z.; Chen, B.; Qian, G. Dual-emitting MOF $\supset$ dye composite for ratiometric temperature sensing. Adv. Mater. 2015, 27, 1420-1425. [CrossRef] [PubMed]

14. Uchiyama, S.; Tsuji, T.; Ikado, K.; Yoshida, A.; Kawamoto, K.; Hayashi, T.; Inada, N. A cationic fluorescent polymeric thermometer for the ratiometric sensing of intracellular temperature. Analyst 2015, 140, 4498-4506. [CrossRef] [PubMed]

15. Chen, Z.; Zhang, K.Y.; Tong, X.; Liu, Y.; Hu, C.; Liu, S.; Yu, Q.; Zhao, Q.; Huang, W. Phosphorescent polymeric thermometers for in vitro and in vivo temperature sensing with minimized background interference. Adv. Funct. Mater. 2016, 26, 4386-4396. [CrossRef]

16. Zhang, H.; Zhang, H.; Jiang, J.; Gao, P.; Yang, T.; Zhang, K.Y.; Chen, Z.; Liu, S.; Huang, W.; Zhao, Q. Dual-emissive phosphorescent polymer probe for accurate temperature sensing in living cells and zebrafish using ratiometric and phosphorescence lifetime imaging microscopy. ACS Appl. Mater. Interfaces 2018, 10, 17542-17550. [CrossRef]

17. Qiao, J.; Chen, C.; Qi, L.; Liu, M.; Dong, P.; Jiang, Q.; Yang, X.; Mua, X.; Mao, L. Intracellular temperature sensing by a ratiometric fluorescent polymer thermometer. J. Mater. Chem. B 2014, 2, 7544-7550. [CrossRef] [PubMed]

18. Hayashi, T.; Fukuda, N.; Uchiyama, S.; Inada, N. A cell-permeable fluorescent polymeric thermometer for intracellular temperature mapping in mammalian cell lines. PLoS ONE 2015, 10, 1-18. [CrossRef]

19. Alkahtani, M.; Alkahtani, M.; Cojocaru, I.; Liu, X.; Herzig, T.; Meijer, J.; Küpper, J.; Lühmann, T. Tin-vacancy in diamonds for luminescent thermometry. Appl. Phys. Lett. 2018, 112, 241902. [CrossRef]

20. Brites, C.D.S.; Millán, A.; Carlos, L.D. Lanthanides in luminescent thermometry. In Handbook on the Physics and Chemistry of Rare Earths; Bunzli, J.-C., Pecharsky, V.K., Eds.; Elsevier: Amsterdam, The Netherlands, 2016; Volume 49, pp. 339-427.

21. Marciniak, L.; Trejgis, K. Luminescence lifetime thermometry with $\mathrm{Mn}^{3+}-\mathrm{Mn}^{4+}$ co-doped nanocrystals. J. Mater. Chem. C 2018, 2, 6061. [CrossRef]

22. Drabik, J.; Cichy, B.; Marciniak, L. New type of nanocrystalline luminescent thermometers based on $\mathrm{Ti}^{3+} / \mathrm{Ti}^{4+}$ and $\mathrm{Ti}^{4+} / \mathrm{Ln}^{3+}\left(\mathrm{Ln}^{3+}=\mathrm{Nd}^{3+}, \mathrm{Eu}^{3+}, \mathrm{Dy}^{3+}\right)$ luminescence intensity ratio. J. Phys. Chem. C 2018, 122, 14928-14936. [CrossRef]

23. Back, M.; Trave, E.; Ueda, J.; Tanabe, S. Ratiometric optical thermometer based on dual near-infrared emission in $\mathrm{Cr}^{3+}$-doped bismuth-based gallate host. Chem. Mater. 2016, 28, 8347-8356. [CrossRef]

24. Kniec, K.; Marciniak, L. The influence of grain size and vanadium concentration on the spectroscopic properties of YAG: $\mathrm{V}^{3+}, \mathrm{V}^{5+}$ and YAG: $\mathrm{V}, \mathrm{Ln}^{3+}\left(\mathrm{Ln}^{3+}=\mathrm{Eu}^{3+}, \mathrm{Dy}^{3+}, \mathrm{Nd}^{3+}\right)$ nanocrystalline luminescent thermometers. Sens. Actuators B Chem. 2018, 264, 382-390. [CrossRef]

25. Peng, H.; Song, H.; Chen, B.; Lu, S.; Huang, S. Spectral difference between nanocrystalline and bulk $\mathrm{Y}_{2} \mathrm{O}_{3}: \mathrm{Eu}^{3+}$. Chem. Phys. Lett. 2003, 370, 485-489. [CrossRef]

26. Song, H.; Wang, J. Dependence of photoluminescent properties of cubic $\mathrm{Y}_{2} \mathrm{O}_{3}: \mathrm{Tb}^{3+}$ nanocrystals on particle size and temperature. J. Lumin. 2006, 118, 220-226. [CrossRef]

27. Winter, M. Periodic Table of the Elements by WebElements. 2018. Available online: http://www.webelements. com. (accessed on 27 February 2018).

28. Elzbieciak, K.; Bednarkiewicz, A.; Marciniak, L. Temperature sensitivity modulation through crystal field engineering in $\mathrm{Ga}^{3+}$ co-doped $\mathrm{Gd}_{3} \mathrm{Al}_{5-\mathrm{x}} \mathrm{Ga}_{x} \mathrm{O}_{12}: \mathrm{Cr}^{3+}, \mathrm{Nd}^{3+}$ nanothermometers. Sens. Actuators $B$ Chem. 2018, 269, 96-102. [CrossRef]

29. Schaack, G.; Konindstein, J.A. Phonon and Electronic Raman Spectra of Cubic Rare-Earth Oxides and Isomorphous Yttrium Oxide. J. Opt. Soc. Am. 1970, 60, 1110-1115. [CrossRef]

30. Liang, H.; Tao, Y.; Xu, J.; He, H.; Wu, H.; Chen, W.; Wang, S.; Su, Q. Photoluminescence of $\mathrm{Ce}^{3+}$, $\mathrm{Pr}^{3+}$ and $\mathrm{Tb}^{3+}$ activated $\mathrm{Sr}_{3} \mathrm{Ln}\left(\mathrm{PO}_{4}\right)_{3}$ under VUV-UV excitation. J. Solid State Chem. 2004, 177, 901-908. [CrossRef]

31. Noculak, A.; Podhorodecki, A.; Pawlik, G.; Banski, M.; Misiewicz, J. Ion-ion interactions in $\beta-\mathrm{NaGdF}_{4}: \mathrm{Yb}^{3+}$, $\mathrm{Er}^{3+}$ nanocrystals-the effect of ion concentration and their clustering. Nanoscale 2015, 7, 13784-13792. [CrossRef]

32. Drabik, J.; Marciniak, L. $\mathrm{KLaP}_{4} \mathrm{O}_{12}: \mathrm{Tb}^{3+}$ Nanocrystals for Luminescent Thermometry in a Single-BandRatiometric Approach. ACS Appl. Nano Mater. 2020, 3, 3798-3806. [CrossRef] 
33. Huang, H.; Sun, X.; Wang, S.; Liu, Y.; Li, X.; Liu, J.; Kang, Z.; Lee, S.T. Strong red emission of pure $\mathrm{Y}_{2} \mathrm{O}_{3}$ nanoparticles from oxygen related defects. Dalt. Trans. 2011, 40, 11362-11366. [CrossRef]

34. Karthikeyan, B.; Sandeep, C.S.S.; Pandiyarajan, T.; Venkatesan, P.; Philip, R. Optical and nonlinear absorption properties of $\mathrm{Na}$ doped $\mathrm{ZnO}$ nanoparticle dispersions. Appl. Phys. Lett. 2009, 95, 023118. [CrossRef] 